\title{
Benign Tumors of the Esophagus: A Histopathologic Study of 49 Cases among 931 Consecutive Esophageal Biopsies
}

\author{
Tadashi Terada
}

\begin{abstract}
The author reviewed 931 consecutive esophageal biopsies in the last 15 year in out pathology laboratory of our hospital in search for benign esophageal tumors. As the results, 41 cases $(4.4 \%)$ of squamous papilloma, 4 cases $(0.4 \%)$ of granular cell tumor, 3 cases $(0.3 \%)$ of leiomyoima, and 1 case $(0.1 \%)$ tubular adenoma were identified. The 41 cases of squamous papillma were located in the cervical esophagus in 6 cases, in the proximal esophagus in 12 cases, in the middle esophagus in 11 cases, and in the distal esophagus in 12 cases. The squamous papilloma was immunohistochemically positive for various cytokeratins. It was endoscopically recognized as small polypoid tumor. The age ranged from 35 years to 81 years with a mean of 51 years. Male to female ratio was 25:16. The 4 cases of granular cell tumor were located in the proximal esophagus in 3 cases, and in the middle esophagus in 1 case. The granular cell tumor was immunohistochemically positive for vimentin, S100 protein, and neuron-specific enolase. It was endoscopically recognized by elevated small lesions. The ages of were $36,45,67$ and 78 years, and male to female ratio was 1:3. The 1 case of tubular adenoma was located in the distal esophagus. Histologically, it was associated with heterotopic gastric mcusa, and immunohistochemically faintly positive for $\mathrm{p} 53$ protein and Ki-67 antigen. It was endoscopically a slightly elevated lesion. The patient was 46 year-old man. The 3 cases of leiomyoma were located in the cervical esophagus in 1 case and in the proximal esophagus in 2 cases. It was immunohistochemically positive for vimentin, $\alpha$-smooth muscle actin, and desmin. It was endoscopically recognized as a submucosal tumor. The ages were 34,45 , and 85 years. Male to female ratio was 1:2.
\end{abstract}

Key words: Esophagus; Benign tumor; Clinicopathology; Immunohistochemistry

Manuscript accepted for publication February 19, 2009.

Department of Pathology, Shizuoka City Shimizu Hospital, Miyakami 1231 Shimizu-Ku, Shizuoka 424-8636, Japan

Email: piyo0111jp@yahoo.co.jp

\section{Introduction}

Many kinds of benign pathologic lesions occur in the esophagus. They include esophageal atresia, heterotopic gastric mucosa, heterotopic pancreatic tissue, diverticula, esophageal cyst, achalasia, Lye stricture, reflex esophagitis, Barrett's esophagus, herpes simplex esophagistis, cytomegalovirus esophagitis, eosiphophilic esophagitis, Crohn's disease, candidiasis, leiomyoma, glycogenic acanthosis, amyloidosis, squamous papilloma, hyperplastic polyp, and granular cell tumor [1,2]. Recent advances in endoscopy have made it possible that these esophageal benign lesions are biopsied and diagnosed correctly. In the present study, the authors reviewed 931 archival cases of the esophageal biopsies in search for benign tumors of the esophagus.

\section{Materials and Methods}

The authors retrospectively reviewed consecutive 931 cases of esophageal biopsy specimens in the last 15 years in the pathology laboratory in our hospital. The ages of the patients ranged from 12 years to 95 years with a mean of 53 years. Male to female ratio was 547:384. Clinical and endoscopic records were also reviewed.

Histochemical stainings including PAS and alcian blue were employed in appropriate cases. In appropriated cases, an immunohistochimical study was performed, using Dako Envision method (Dako Corp., Glostrup, Denmark), as previously described $[3,4]$. The antibodies employed were anti-cytokeratin (AE1/3, Dako), anti-cytokeratin (polyclonal wide, Dako), anti-p53 protein (DO-7, Dako), anti-Ki-67 antigen (MIB-1, Dako), neuron-specific enolase (BBS/NC/VIH14, Dako), CD34 (QBEND10, Dako), vimentin (Vim 3B4, Dako), desmin (D33, Dako), $\alpha$-smooth muscle actin (1A4, Dako), S100 protein (polyclonal, Dako) KIT (polyclonal, Dako), and PDGFRA (Santa Cruz, CA, USA).

\section{Results}




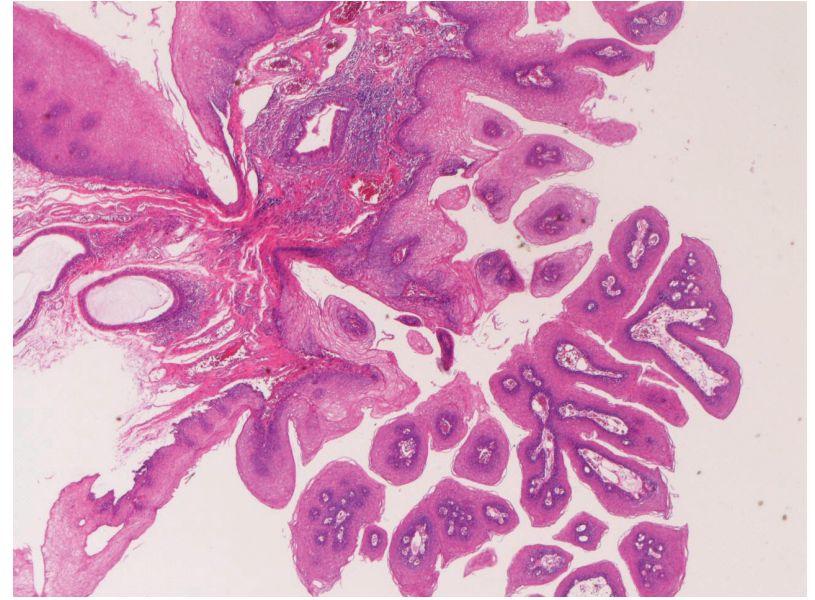

Figure 1. Squamous papilloma of the esophagus. Papillary proliferation of mature squamous epithelium is seen. HE, x20

Forty-one cases (4.4\%) of squamous papilloma, 4 cases $(0.4 \%)$ of granular cell tumor, 3 cases $(0.3 \%)$ of leiomyoima, and 1 case $(0.1 \%)$ tubular adenoma were identified.

In the 41 cases of squamous papilloma, the age ranged from 35 years to 81 years with a mean of 51 years. Male to female ratio was $25: 16$. The presenting symptoms were asymptomatic in 32 cases, nausea in 4 cases, chest burn in 3 cases, and dysphasia in 2 cases. The locations of the 41 cases of squamous papilloma were the cervical esophagus in 6 cases, the proximal esophagus in 12 cases, the middle esophagus in 11 cases, and the distal esophagus in 12 cases. Squamous papilloma was endoscopically recognized as small polypoid tumor. The size of squamous pailloma ranged from
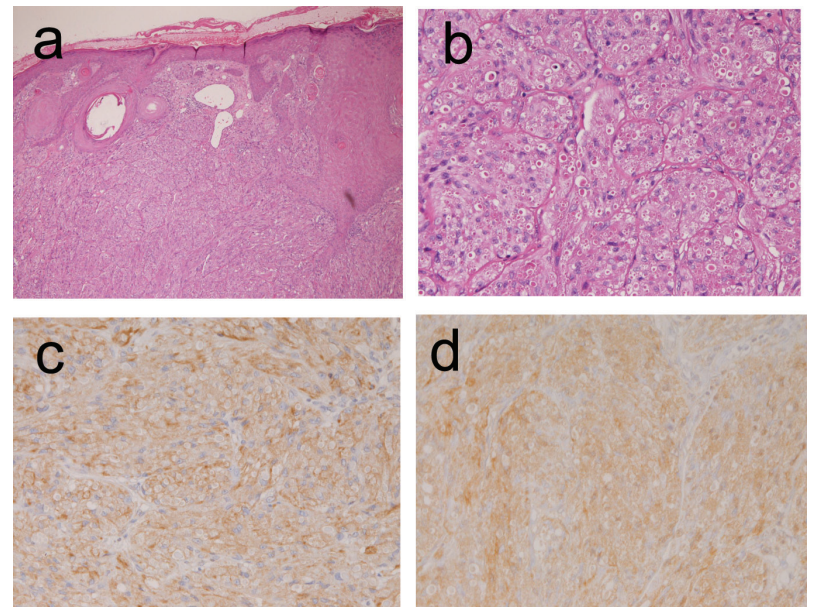

Figure 2. Granular cell tumor of the esophagus. A: Histologic features. Large cells with acidophilic granular cytoplasm are seen. Many hyaline globules are also seen. HE, x200 B: The cytoplasm and hyaline globules are positive with PAS stain. PAS, x200 C: The tumor cells are positive for $\mathrm{S} 100$ protein. Immunostaining, x200 D: The tumor cells are positive for neuron-specific enolase. Immunostaining, $x 200$.
$2 \mathrm{~mm}$ to $10 \mathrm{~mm}$. Histologically, squamous papilloma was characterized in papillary proliferation of mature squamous epithelium (Fig 1). No koilocytosis was identified in this series. The squamous papilloma was immunohistochemically positive for various cytokeratins and negative for vimentin and other antigens examined.

In the 4 cases of granular cell tumor, the ages of the patients were 36, 45, 67 and 78 years, and male to female ratio was 1:3. Two cases complained of dysphagia and two cases were asymptomatic. They were located in the proximal esophagus in 3 cases, and in the middle esophagus in 1 case. Granular cell tumor was endoscopically recognized by an elevated small lesion. The size ranged from $4 \mathrm{~mm}$ to 12 $\mathrm{mm}$. Histologically, granular cell tumors were characterized by a proliferation of large cells with acidphilic granular cytoplasm (Fig 2a). Hyaline globules positive with PAS stains were recognized in many areas (Fig $2 b$ ). The granular cell tumors were immunohistochemically positive for vimentin, S100 protein (Fig 2c), and neuron-specific enolase (Figure $2 d$ ), and negative for cytokeratins and other antigens examined.

In the 1 case of tubular adenoma, the patient was 46 years old man. He was asymptomatic. The tubular adenoma was located in the distal esophagus. It was endoscopically a slightly elevated lesion. Histologically, it was composed of adenomatous proliferation (Fig 3a) reminiscent of gastric or colonic adenoma. Interestingly, it was associated with heterotopic gastric mucosa. Immunohistochemically, it was faintly positive for p53 protein (Fig 3b). The Ki-67 labeling was $26 \%$ (Fig 3c).

In the 3 cases of leiomyoma, the ages were 34,45 , and 85 years. Male to female ratio was 1:2. The leiomyoma were located in the cervical esophagus in 1 case and in the proximal esophagus in 2 cases. It was endoscopically recognized as a submucosal tumor. The sizes were $4 \mathrm{~mm}, 6 \mathrm{~mm}$, and $12 \mathrm{~mm}$. Histologically, leiomyoma was characterized by well defined nodule (Figure 4A), composed of spindle smooth muscles (Figure 4B). No atypia or mitotic figures were identified. The leiomyoma was immunohistochemically positive for vimentin, $\alpha$-smooth muscle actin, and desmin ( 1 case), but negative for cytokeratins, CD34, KIT, and PDGFRA.

\section{Discussion}

Benign tumors of the esophagus are rare, and most of them are not clinically important lesions. However, differential diagnosis is important. In addition, large benign tumors may obstruct the esophageal lumen, and treatment was difficult in such cases.

Squamous papilloma of the esophagus is a rare lesion. Most of the previously reported study was case reports and studies of small series [5-9]. The squamous papilloma of the esophagus does not transform into squamous cell carcinoma. 

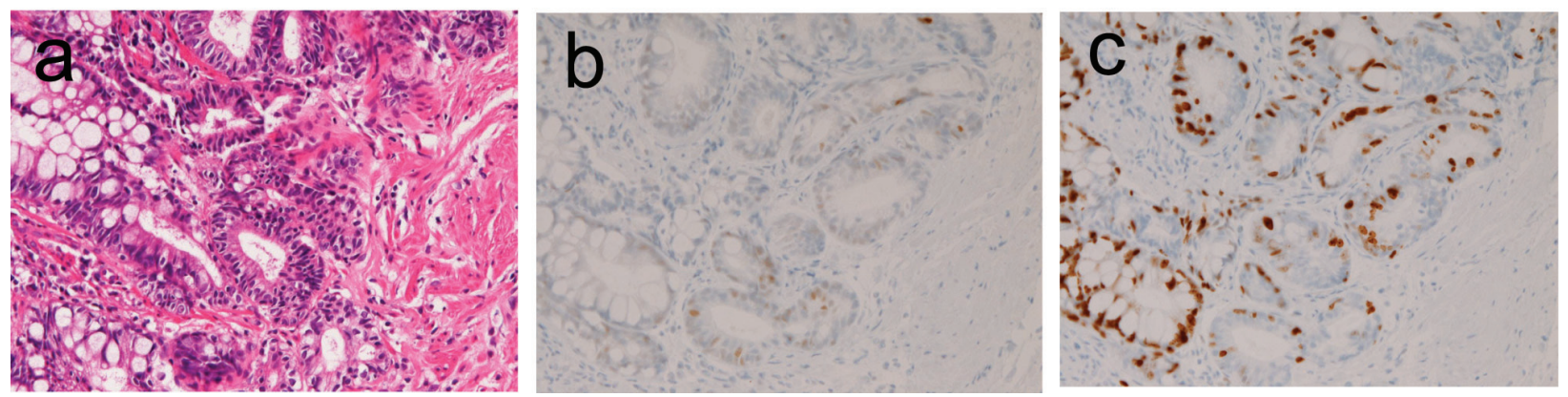

Figure 3. Tubular adenoma of the esophagus. A: adenomatous tubules are seen. HE, x200 B: The tumor cells are very focally positive for p53 protein. Immunostaining, x100 C: The Ki-67 labeling is $26 \%$. Immunostaining (MIB1), x200

In the present study, the frequency was $4.4 \%$, and the size was small. The hot debate is whether or not the squamous cell carcinoma is caused by human papilloma virus. Some researchers insisted the association of squamous papilloma and human papilloma virus $[5,7,8]$, but others denied the association [6]. In the present study, although no viral examination was performed, koilocytosis as seen in uterine cervix neoplasm and condyloma acuminatum was not recognized.

Granular cell tumor of the esophagus is extremely rare. Only several case reports or studies of small series have been published [10-12]. Its important point is differential diagnosis. In general, acidophilic granular cytoplasm and immunoreactions for vimentin, S100 protein, and neuron-specific enolase are important points in this tumor. The present 4 cases fulfilled the diagnostic criteria of granular cell tumor. The frequency in the present study was $0.4 \%$.

Tubular adenoma of the esophagus is extremely rare. Only a few case reports are present in the literature [13]. In the present study, it is very interesting that the tubular adenoma was associated with heterotopic gastric mcuosa $[14,15]$.

Adenocarcinoma very infrequently develops in the heterotopic gastric mucosa [16, 17]. However, adenoma developing in heterotopic gastric mucosa has not been reported, to the author's best knowledge. In the present study, it frequency was $0.1 \%$.

Three leiomyomas were recognized in the present study.
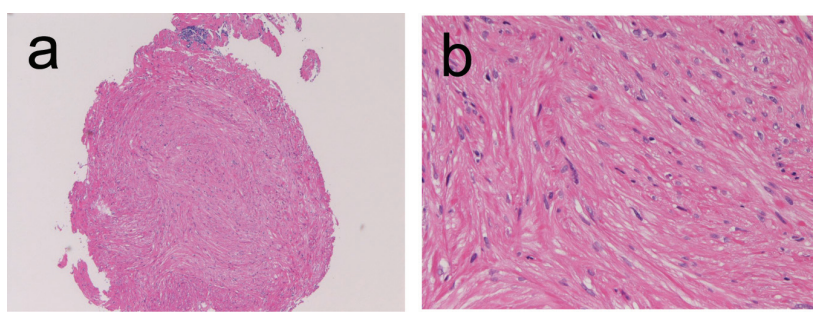

Figure 4. Leiomyoma of the esophagus. A: Low power view shows well-define nodule composed of acidophilic spindle cells. HE, x40 $\mathrm{B}$ : The tumor is composed of spindle cells considered as smooth muscle cells. HE, x200
Esophageal leiomyoma is rare but the most common mesenchymal tumor. In the literature, several case reports are recorded $[18,19]$. Large leiomyoma may obstruct the esophageal lumen, causing serious problems. The most important points of esophageal leiomyoma are differential diagnosis from leiomyosarcoma and gastrointestinal stromal tumor (GIST). In making a diagnosis of leiomyoma, mitotic counts, cellular atypia, and necrosis were required. In the present case, no atypia or mitotic figures were present. Leiomyoma must be distinguished from GIST. In making a diagnosis of GIST, immunohistochemical demonstration of KIT and/or CD 34 is mandatory [20, 21]. In addition, genetic analysis of KIT and PDGFRA genes may be required in KIT-negative GIST cases. The present cases were negative for KIT, CD34, and PDGFRA. Therefore the present cases are true leiomyomas.

\section{Acknowledgement}

The author has no conflict of interest.

\section{References}

1. Rosai J. Esophagus. In: Rosai and Ackermann's Pathology. Ninth edition, Mosby. p615-647.

2. Tumours of oesophagus. Chapter 1. Hamilton SR and Aaltonen LA eds, WHO Classification of tumours. Pathology and genetics, Tumor of the digestive system. IARC press, Lyon, 2000. p10-30.

3. Terada T, Kawaguchi M. Primary clear cell adenocarcinoma of the peritoneum. Tohoku J Exp Med 2005;206:271-275.

4. Terada T, Kawaguchi M, Furukawa K, Sekido Y, Osamura Y. Minute mixed ductal-endocrine carcinoma of the pancreas with predominant intraductal growth. Pathol Int 2002;52:740-746.

5. Odze R, Antonioli D, Shocket D, Noble-Topham S, Goldman H, Upton M. Esophageal squamous papillo- 
mas. A clinicopathologic study of 38 lesions and analysis for human papillomavirus by the polymerase chain reaction. Am J Surg Pathol 1993;17:803-812.

6. Carr NJ, Bratthauer GL, Lichy JH, Taubenberger JK, Monihan JM, Sobin LH. Squamous cell papillomas of the esophagus: a study of 23 lesions for human papillomavirus by in situ hybridization and the polymerase chain reaction. Hum Pathol 1994;25:536-540.

7. Poljak M, Orlowska J, Cerar A. Human papillomavirus infection in esophageal squamous cell papillomas: a study of 29 lesions. Anticancer Res 1995;15:965-969.

8. Bohn OL, Navarro L, Saldivar J, Sanchez-Sosa S. Identification of human papillomavirus in esophageal squamous papillomas. World J Gastroenterol 2008;14:71077111.

9. Takeshita K, Murata S, Mitsufuji S, Wakabayashi N, Kataoka K, Tsuchihashi Y, Okanoue T. Clinicopathological characteristics of esophageal squamous papillomas in Japanese patients--with comparison of findings from Western countries. Acta Histochem Cytochem 2006;39:23-30.

10. Narra SL, Tombazzi C, Datta V, Ismail MK. Granular cell tumor of the esophagus: report of five cases and review of the literature. Am J Med Sci 2008;335:338-341.

11. Voskuil JH, van Dijk MM, Wagenaar SS, van Vliet AC, Timmer R, van Hees PA. Occurrence of esophageal granular cell tumors in The Netherlands between 1988 and 1994. Dig Dis Sci 2001;46:1610-1614.

12. Goldblum JR, Rice TW, Zuccaro G, Richter JE. Granular cell tumors of the esophagus: a clinical and patholog- ic study of 13 cases. Ann Thorac Surg 1996;62:860-865.

13. Bajbouj M, von Weyhern C, Becker V, Seidl S, Ott R, Schatke W, Fend F, et al. True adenomas of the cardia: a case series of 3 patients. Digestion 2008;77:65-67.

14. Borhan-Manesh F, Farnum JB. Incidence of heterotopic gastric mucosa in the upper oesophagus. Gut 1991;32:968-972.

15. Jabbari M, Goresky CA, Lough J, Yaffe C, Daly D, Cote $\mathrm{C}$. The inlet patch: heterotopic gastric mucosa in the upper esophagus. Gastroenterology 1985;89:352-356.

16. Russin V, Krevsky B, Caroline DF, Tang CK, Ming SC. Mixed hyperplastic and adenomatous polyp arising from ectopic gastric mucosa of the duodenum. Arch Pathol Lab Med 1986;110:556-558.

17. Abe T, Hosokawa M, Kusumi T, Kusano M, Hokari K, Kagaya H, Watanabe A, et al. Adenocarcinoma arising from ectopic gastric mucosa in the cervical esophagus. Am J Clin Oncol 2004;27:644-645.

18. Mutrie CJ, Donahue DM, Wain JC, Wright CD, Gaissert HA, Grillo HC, Mathisen DJ, et al. Esophageal leiomyoma: a 40-year experience. Ann Thorac Surg 2005;79:1122-1125.

19. Fountain SW. Leiomyoma of the esophagus. Thorac Cardiovasc Surg 1986;34:194-195.

20. Hirota S, Isozaki K. Pathology of gastrointestinal stromal tumors. Pathol Int 2006;56:1-9.

21. Miettinen M, Lasota J. Gastrointestinal stromal tumors: review on morphology, molecular pathology, prognosis, and differential diagnosis. Arch Pathol Lab Med 2006;130:1466-1478. 